\title{
Potassium channel openers and prostacyclin play a crucial role in mediating the vasorelaxant activity of Gynura procumbens
}

Hien-Kun Ng, Ting-Fung Poh, Sau-Kuen Lam and See-Ziau Hoe*

\begin{abstract}
Background: Previous studies of Gynura procumbens (G. procumbens) have shown that partially purified fractions of the leaves are capable of lowering the blood pressure of rats by inhibiting angiotensin-converting enzymic activity and causing vasodilatation. The objectives of this study were therefore to further purify the active compounds that exhibited selective effects on blood vessels, determine the mechanism of actions, and to qualitatively analyse the putative compounds present.
\end{abstract}

Methods: The butanolic fraction (BU) of the crude ethanolic extract was purified using column chromatography to obtain several sub-fractions of different polarities. The in vitro effects of $\mathrm{BU}$ and the sub-fractions on vascular tension were subsequently determined using isolated rat thoracic aortic rings. The most potent sub-fraction (F1) alone was then investigated for its mechanisms of the vasorelaxant activity. In another experiment, thin-layer chromatography was used to qualitatively analyse the active compounds found in F1.

Results: The BU and the sub-fractions ranging from $10^{-7}$ to $10^{-2} \mathrm{~g} / \mathrm{ml}$ significantly $(p<0.05)$ inhibited the sustained tonic contractions induced by phenylephrine and potassium chloride in a concentration-dependent manner with various degree of potency. The most potent sub-fraction (F1) antagonised the calcium-induced vasocontractions $\left(1 \times 10^{-4}-1 \times 10^{-2} \mathrm{M}\right)$ in calcium-free with high concentration of potassium as well as in calcium- and potassium-free Krebs-Henseleit solutions. Contractions induced by noradrenaline and caffeine were not affected by F1. The vasorelaxing effect caused by F1 was significantly attenuated with preincubation of potassium channel blockers (glibenclamide and 4-aminopyridine) and prostacyclin inhibitor (indomethacin) while it was not affected by preincubation with tetraethylammonium, I-nitro-arginine methyl esther, propanolol, atropine, oxadiazolo quinoxalin one and methylene blue. The qualitative phytochemical analysis of F1 indicated the presence of flavonoids.

Conclusion: These results confirm previous findings that $G$. procumbens causes vasodilatory effects by blocking calcium channels. In addition, the present study further demonstrates that the vasodilatory effect of G. procumbens may also be due to the opening of potassium channels and the stimulation of prostacyclin production. The putative compounds are probably flavonoids in nature.

Keywords: Gynura procumbens, Vasodilation, Calcium channel, Potassium channel, Prostacylin

\footnotetext{
*Correspondence: hoesz@ummc.edu.my

Department of Physiology, Faculty of Medicine, University of Malaya, Kuala Lumpur, Malaysia
} 


\section{Background}

Hypertension is defined as a condition where there is persisting high arterial pressure with systolic and diastolic blood pressure (BP) exceeding $140 \mathrm{mmHg}$ and $90 \mathrm{mmHg}$ respectively [1]. Hypertension is a high prevalent risk factor for cardiovascular diseases (CVD) throughout the industrial world and it is becoming a common health problem worldwide because of increasing longevity and the prevalence of contributing factors such as obesity, physical inactivity, and unhealthy diets. Cardiovascular disease is responsible for one third of global deaths and is a leading contributor to the global disease burden [2]. Therefore, the search for a safe and effective method for controlling hypertension has been a continuous effort world-wide. In addition to conventional synthetic drugs like thiazide and captopril [3], naturally occurring compounds from plant origin have also been highly sought by researchers.

One of the major determinants of $\mathrm{BP}$ is the total peripheral resistance (TPR), which is determined by the contractile state of blood vessel or vascular tone. In view of its defining role in regulating $\mathrm{BP}$, vascular reactivity has become a target in treating hypertension. With the advent of the direct vasodilator, hydralazine, in the early 1950s [4], many drugs that can cause vascular relaxation have been developed, including some plant-derived compounds.

Gynura procumbens (G. procumbens) (Lour.) Merr. or the local names of sambung nyawa (Malay) or jian wei feng (Chinese), from the family of Compositae, and a fast growing herbaceous plant, is found in Borneo, Java, the Philippines and Peninsular Malaysia. The plant is widely used to treat kidney diseases, rashes and fever and the leaves of the plant have been used in folk medicine as an antihypertensive agent [5].

A lot of effort and studies have been carried out in order to scientifically prove the pharmacological properties of G. procumbens. Ethanolic extract of G. procumbens leaves have been shown to possess antihyperglycaemic and antihyperlipidaemic activities in diabetic rats [6,7], and the $n$-butanol fraction from the G. procumbens leaves also has hypoglycaemic effects [8]. Another study had shown that hexane and ethyl acetate fractions have potential in stimulating glucose uptake in 3 T3-F44 adipocytes [9]. Steroids isolated from the plant have been proven to possess antiinflammatory activity [10]. Furthermore, ethanolic extract of it has demonstrated anti-ulcerogenic activity [11] and was able to inhibit ultraviolet (UV) B-induced matrix-metalloproteinase expression in human dermal fibroblasts [12]. Methanolic extract of G. procumbens has been categorised as a no-observed-adverse-effect level (NOAEL) crude drug that acts harmlessly and is considered to be of no toxicological concern [13]. Its aqueous extract appears to inhibit human mesangial cell proliferation [14].
Gynura procumbens has also been found to demonstrate antihypertensive activities in rat [15] by inhibiting ACE activity [16] and cause vasodilation via inhibition of calcium channels [17].

The main purpose of the present study was to further purify the active compounds that exhibit selective effects on the blood vessels, determine the mechanism of actions, and to qualitatively analyse the putative compounds present.

\section{Methods}

\section{Plant material}

Fresh G. procumbens were collected from the southern part of Peninsular Malaysia and authenticated by the Institute of Biological Sciences, University of Malaya. A voucher specimen (KLU 047690) had been deposited in the Herbarium at Rimba Ilmu, University of Malaya.

\section{Animals}

Adult male SD rats, weighing from $200-300$ g, were obtained from the Experimental Animal Center, University of Malaya. All the rats were kept under standard condition, given standard rat chow and tap water ad libitum. All experimental procedures that involve animal studies were approved by the University of Malaya Medical Center Animal Ethics Committee (FIS/14/10/2009/NHK (R)).

\section{Drug and chemicals}

For extraction and fractionation processes, ethanol, ethyl acetate, hexane, methanol, and $n$-butanol were purchased from R \& M Marketing, Essex, U.K. For the in vitro aortic ring pharmacological intervention, 4aminopyridine, acetylcholine chloride (ACh), ACE, atropine sulphate, Brilliant Blue-G dye, caffeine anhydrous, glibenclamide, indomethacin, L-nitro-arginine methyl ester (L-NAME), noradrenaline (NA), oxadiazolo quinoxalin one (ODQ), phenylehprine (PE), propranolol hydrochloride, tetraethylammonium (TEA) were purchased from Sigma-Aldrich CO., St Loius, MO, USA. Ingredients for Krebs-Henseleit (K-H) solution were purchased from Merck KGaA, Darmstadt, Germany. All water-soluble drugs were dissolved in the distilled water before use while the waterinsoluble drugs were dissolved in 15\% tween 80 solution.

\section{Extraction and purification}

The leaves of the plant were washed, cleaned of adulterants and dried in an oven at $40^{\circ} \mathrm{C}$ for 72 hours. The dried leaves were then ground into fined powder using a grinder. Crude ethanolic extract was obtained by macerating the powder with $95 \%$ ethanol at room temperature for 3 days. The extract was then concentrated by using rotary evaporator and reconstituted in $80 \%$ aqueous ethanol. The resulting fraction was then partitioned with hexane for the removal of the lipid or non-polar compounds. The hexanic phase was 
collected and dried in vacuo to produce the hexanic fraction $(\mathrm{HX})$. The aqueous ethanolic phase obtained was subjected to evaporation to remove the ethanol and produce the aqueous solution that contained ethanol-soluble precipitate $(\mathrm{EH})$. The precipitate was then filtered out and the remaining solution was partitioned again with watersaturated $n$-butanol. The butanolic phase was then dried using the rotary evaporator and lyophilised to obtain BU whilst the remaining aqueous phase was lyophilised to obtain the final aqueous fraction (FA). Since the fraction BU showed the highest vasorelaxing activities from previous studies [17], it was subjected to further purification.

The BU was further purified by using column chromatography packed with silica gel $60(0.063-0.200 \mathrm{~nm})$ as the stationary phase. It was dissolved in ethanol and applied to the packed column. Eight different solvent mixtures that consisted of different proportions of ethyl acetate, methanol and water were used as the mobile phases of the column chromatography with the polarities increasing from mobile phases 1 to 8 . Each sub-fraction

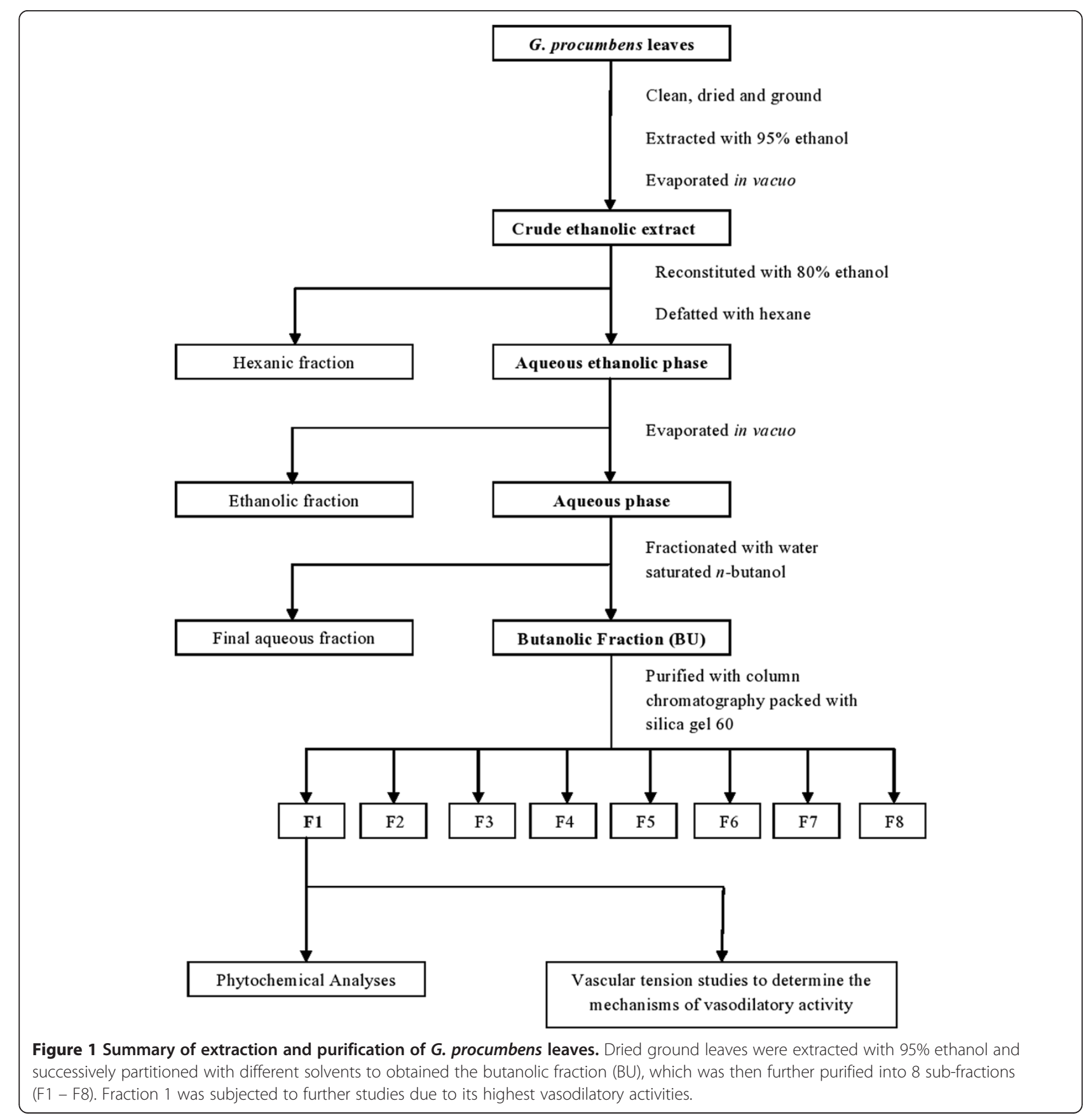


obtained was tested for vasorelaxing activities and the most active fraction was subjected to further studies. Figure 1 shows the flow chart of extraction, fractionation and purification procedures of the crude extract of G. procumbens leaves.

\section{Phytochemical screening}

The sub-fraction that achieved the highest activity in the vasorelaxing effect was subjected to phytochemical screening by thin layer chromatography (TLC). The stationary phase used was TLC plate pre-coated with silica gel $60 \mathrm{~F}_{254}$ on aluminium sheets and the mobile phase used was a mixture of ethyl acetate (75\%), methanol (10\%), deionised water (10\%) and formic acid (5\%). Naturstoff reagent, ninhydrin reagent, and diphenylamine-anilinephosphoric acid reagent were used for the detection of flavonoids, proteins, and sugar moieties respectively.

\section{In vitro vascular tension studies}

Male SD rats weighing 250 - 300 g were sacrificed by cervical dislocation and the thoracic aorta was located. The throracic aorta was isolated and immediately placed in an oxygenated $\mathrm{K}-\mathrm{H}$ solution made up of the following composition (in $\mathrm{mM}$ ): $\mathrm{NaCl}, 118.0 ; \mathrm{KCl}, 4.70 ; \mathrm{CaCl}_{2}, 1.25$; $\mathrm{MgSO}_{4}, 1.2 ; \mathrm{KH}_{2} \mathrm{PO}_{4}, 1.2 ; \mathrm{NaHCO}_{3}, 24.9$ and glucose, 11.1. Adhering fat and connective tissue were carefully removed and the aorta was cut into rings of $1-3 \mathrm{~mm}$ in length. The aortic ring was mounted by 2 stainless steel holders in an organ bath containing $10 \mathrm{ml} \mathrm{K-H}$ solution and continuously bubbled with $95 \%$ oxygen and $5 \%$ carbon dioxide gas mixture. The $\mathrm{K}-\mathrm{H}$ solution was maintained at $37^{\circ} \mathrm{C}$ by a circulating water bath system. One of the holders was served as an anchor while the other side was connected to a force transducer to measure the isometric tension developed. The force transducer was connected to a Powerlab system which displayed the responses onto the screen of a personalised computer that was installed with the software Powerlab Chart version 5.0.

A basal tension of $1 \mathrm{~g}$ was applied to each ring. Each preparation was allowed to equilibrate for 60 minutes with the changing of the $\mathrm{K}-\mathrm{H}$ solution every 15 minutes before the start of the experiments. Aortic rings were stimulated with $\mathrm{KCl}\left(6 \times 10^{-2} \mathrm{M}\right)$ for 3 times to confirm the production of reproducible contractile responses. Aortic rings were denuded to remove the endothelial layer in some preparations by inserting a pair of forceps into the lumen of the aorta and gently rotating them. The viability of each aortic ring was validated by precontraction of PE $\left(1 \times 10^{-6} \mathrm{M}\right)$ and relaxed by $\mathrm{ACh}$ $\left(1 \times 10^{-5} \mathrm{M}\right)$ just before the experiment. Relaxation of $\geq 70 \%$ indicated the presence of a functional or intact endothelial layer while the lack of relaxation indicated the successful removal of the layer.

\section{Effects of BU and sub-fractions (F1 - F8) on aortic rings precontracted with $\mathrm{PE}$ or $\mathrm{KCl}$}

The intact aortic rings were precontracted by the addition of PE $\left(1 \times 10^{-6} \mathrm{M}\right)$ or $\mathrm{KCl}\left(8 \times 10^{-2} \mathrm{M}\right)$. After the tonic responses or contractions became stable, increasing concentrations of the test fractions $\left(10^{-7}-10^{-2} \mathrm{~g} / \mathrm{ml}\right)$ were added cumulatively. F1 was subjected to further studies due to its highest activity in producing the vasorelaxing effect.

\section{Effects of $\mathrm{F} 1$ on calcium $\left(\mathrm{Ca}^{2+}\right)$ channel activities}

In order to investigate whether F1 could interfere with the influx of $\mathrm{Ca}^{2+}$ through voltage-dependent calcium channel (VDCC), aortic rings were exposed to $\mathrm{Ca}^{2+}$-free solution in the presence of potassium ion $\left(\mathrm{K}^{+} ; 6 \times 10^{-2} \mathrm{M}\right)$. The preparation of the solution had the same composition with the normal $\mathrm{K}-\mathrm{H}$ solution except that $\mathrm{CaCl}_{2}$ was excluded and EDTA $\left(1 \times 10^{-4} \mathrm{M}\right)$ added to eliminate the extracellular $\mathrm{Ca}^{2+}$. Each aortic ring was exposed to this solution for $60 \mathrm{mi}-$ nutes. Two successive cumulative concentration-response curves for $\mathrm{Ca}^{2+}\left(1 \times 10^{-4}-1 \times 10^{-2} \mathrm{M}\right)$ were obtained. The first curve was obtained without the incubation of F1, after which the aortic ring was washed and allowed to equilibrate for 60 minutes in the solution. Two different concentrations of F1 $(2.0 \mathrm{mg} / \mathrm{ml}$ and $4.0 \mathrm{mg} / \mathrm{ml})$ were added to the organ bath and allowed to incubate for 30 minutes, after which the second curve was obtained. Each aortic ring was exposed to only one concentration of F1.

To investigate the inhibitory effect of $\mathrm{F} 1$ on receptoroperated calcium channel (ROCC), $\mathrm{Ca}^{2+}$ - and $\mathrm{K}^{+}$-free $\mathrm{K}-\mathrm{H}$ solution was used in the experiment. The composition of the solution was the same with $\mathrm{Ca}^{2+}$-free $\mathrm{K}-\mathrm{H}$ solution except that $1.2 \mathrm{mM}$ of $\mathrm{NaH}_{2} \mathrm{PO}_{4}$ was used to replace the $1.2 \mathrm{mM}$ of $\mathrm{KH}_{2} \mathrm{PO}_{4}$. After the equilibration, $\mathrm{PE}\left(1 \times 10-{ }^{6} \mathrm{M}\right)$ was added to induce a transient contraction. As the contraction became stable, cumulative concentrations of $\mathrm{Ca}^{2+}\left(1 \times 10^{-4}-1 \times 10^{-2} \mathrm{M}\right)$ were added to obtain the first curve. After that, the aortic ring was washed with normal $\mathrm{K}-\mathrm{H}$ solution and incubated for 45 minutes. The solution was then replaced with $\mathrm{Ca}^{2+}$ and $\mathrm{K}^{+}$-free $\mathrm{K}-\mathrm{H}$ solution. Two different concentrations of F1 $(2.0 \mathrm{mg} / \mathrm{ml}$ and $4.0 \mathrm{mg} / \mathrm{ml})$ were added to the organ bath and allowed to incubate for 30 minutes. $\mathrm{Cu}$ mulative concentrations of $\mathrm{Ca}^{2+}$ were added to obtain the second curve. Each aortic ring was exposed to only one concentration of F1.

To elucidate whether the F1 could affect the release of $\mathrm{Ca}^{2+}$ from intracellular store, NA and caffeine were used. The aortic ring was exposed to $\mathrm{Ca}^{2+}$ - free $\mathrm{K}-\mathrm{H}$ solution for 15 minutes after the equilibration in normal $\mathrm{K}-\mathrm{H}$ solution. Noradrenaline $\left(1 \times 10^{-6} \mathrm{M}\right)$ or caffeine $\left(4.5 \times 10^{-2} \mathrm{M}\right)$ was added to induce a transient contraction. The ring was then washed and incubated with normal $\mathrm{K}-\mathrm{H}$ solution for 45 minutes to replenish the intracellular $\mathrm{Ca}^{2+}$ store. After that, the medium was replaced with $\mathrm{Ca}^{2+}$ - free $\mathrm{K}-\mathrm{H}$ 
solution and allowed to equilibrate for 15 minutes. Noradrenaline or caffeine was added after the incubation with F1 $(2.0 \mathrm{mg} / \mathrm{ml}$ and $4.0 \mathrm{mg} / \mathrm{ml})$ for 15 minutes. Each aortic ring was exposed to only one concentration of F1.

\section{Effects of $\mathrm{F} 1$ on potassium $\left(\mathrm{K}^{+}\right)$channel activities} In order to investigate whether the F1 could affect the $\mathrm{K}^{+}$ channel opening during vasorelaxation, 4-aminopyridine $(1 \mathrm{mM})$, a blocker of the voltage-activated $\mathrm{K}^{+}$channel; TEA $(1 \mathrm{mM})$, a selective blocker to $\mathrm{Ca}^{2+}$-activated $\mathrm{K}^{+}$channel; and glibenclamide $(10 \mu \mathrm{M})$, a blocker of ATP-sensitive $\mathrm{K}^{+}$ channel were used in the experiments. All of the blockers were added in the organ bath 15 minutes before the aortic rings were precontracted with PE. After the tonic contractions had become stable, increasing concentrations of F1 $\left(10^{-7}-10^{-2} \mathrm{~g} / \mathrm{ml}\right)$ were added cumulatively. The relaxation curves obtained were then compared with the control curve which were not treated with any of the blockers. Each aortic ring was exposed to only one blocker [18].

\section{Effects of $\mathrm{F} 1$ on the endothelium-denuded aortic rings precontracted with $\mathrm{PE}, \mathrm{NO}$ and prostacyclin productions, and guanylyl cyclase activity}

To study the involvement of endothelium in the vasorelaxation effect of F1, endothelium-denuded aortic rings were used. The denuded aortic rings were precontracted with PE before cumulative doses of F1 were added. After the tonic contractions became stable, increasing concentrations of F1 $\left(10^{-7}-10^{-2} \mathrm{~g} / \mathrm{ml}\right)$ were added cumulatively.

The possible inhibitory effects of $\mathrm{F} 1$ on the release of two endothelium-derived releasing factor (EDRF), NO and prostacyclin, as well as its effect on the guanylyl cyclase, a key enzyme in the NO-mediated vasodilation pathway, were also investigated. In these series of experiments, the NO synthase inhibitor, L-NAME; the non-selective inhibitor of prostacyclin production, indomethacin; as well as two of the guanylyl cyclase inhibitors; ODQ and methylene blue, were used.

After the endothelium-intact aortic rings had equilibrated, the drugs were added to the organ bath 15 minutes before the addition of PE. As the PE-induced contraction reached a steady stage, increasing concentration of F1 $\left(10^{-7}-10^{-2} \mathrm{~g} / \mathrm{ml}\right)$ were added cumulatively. The relaxation curves obtained were compared to the control curve [19]. Each aortic ring was exposed to only one type of drug.

\section{Effects of F1 on autonomic receptor activities}

To study whether the vasodilation activity of $\mathrm{F} 1$ is related to autonomic receptors, propranolol $(1 \mu \mathrm{M})$, a beta adrenoceptor blocker and atropine $(1 \mu \mathrm{M})$, a muscarinic receptor blocker, were used. Both drugs were added to the organ bath 15 minutes before the addition of PE. After the tonic contractions caused by PE became stable, increasing concentrations of $\mathrm{F} 1\left(10^{-7}-10^{-2} \mathrm{~g} / \mathrm{ml}\right)$ were added cumulatively. Each aortic ring was exposed to only one type of drug.

\section{Statistical analysis}

Changes in the relaxation were calculated as percentage change of maximal contraction induced by $\mathrm{PE}$ or $\mathrm{KCl}$. The $\mathrm{pIC}_{50}$ value is calculated as the concentration of $\mathrm{BU}$ or $\mathrm{F} 1$ to produce $50 \%$ reduction of the maximal contraction induced by $\mathrm{PE}$ or $\mathrm{KCl}$. For the cumulative dose-response curves of $\mathrm{Ca}^{2+}$, data from experiments in the presence or absence of the test fraction were compared. The maximal contraction $\left(E_{\max }\right)$ obtained in the 1st response curve of $\mathrm{Ca}^{2+}$ was taken as $100 \%$ and all the following contractions were calculated as a percentage of these values. The concentration of $\mathrm{Ca}^{2+}$ required to produce $50 \%$ of the maximal contraction was taken as $\mathrm{pEC}_{50}\left(-\log \mathrm{EC}_{50}\right)$.

In the experiment that involved NA and caffeine, changes in NA- or caffeine-induced contractions in the presence of F1 were expressed as percentages of the initial contraction before incubation of F1. All the analyses were performed by computer program Graphpad Prism 5 using non-linear regression of concentration-response curve. All values are expressed as mean \pm S.E.M for $n$ numbers of rings. Statistical differences are evaluated by Student $t$-test. A probability level of less than $0.05(\mathrm{p}<0.05)$ is considered to be significantly different.

\section{Results}

\section{Extraction and purification}

Extraction of dried G. procumbens leaves with 95\% ethanol and the subsequent fractionation lead to the production of various fractions with different percentage of yields. The yield obtained from BU was approximately $2 \%$. Further purification of BU using column chromatography resulted in 8 sub-fractions (F1 - F8) of which F1, F2 and F3 contributed to most of the yields, accounting for $20 \%, 24 \%$ and $35 \%$ respectively.

\section{Phytochemical screening}

High amount of flavonoids, which fluoresce under ultraviolet light at $365 \mathrm{~nm}$ after spraying with Naturstoff reagent, were detected.

\section{Effects of BU and sub-fractions (F1 - F8) on aortic ring precontracted with $\mathrm{PE}$ or $\mathrm{KCl}$}

The $\mathrm{BU}$ fraction at the concentrations ranging from $10^{-7}-10^{-2} \mathrm{~g} / \mathrm{ml}$ significantly $(\mathrm{p}<0.05)$ inhibited the sustained tonic contraction induced by $\mathrm{PE}$ and $\mathrm{KCl}$ in a concentration-dependent manner. The maximal relaxation responses caused by $\mathrm{BU}$, or $\mathrm{R}_{\max }$, in the aortic rings precontracted with $\mathrm{PE}$ and $\mathrm{KCl}$ were $85.39 \pm$ $4.26 \%$ and $53.30 \pm 6.14 \%$, respectively and the $\mathrm{pIC}_{50}$ values were $2.57 \pm 0.06$ and $2.06 \pm 0.08$, respectively (Figure 2). 


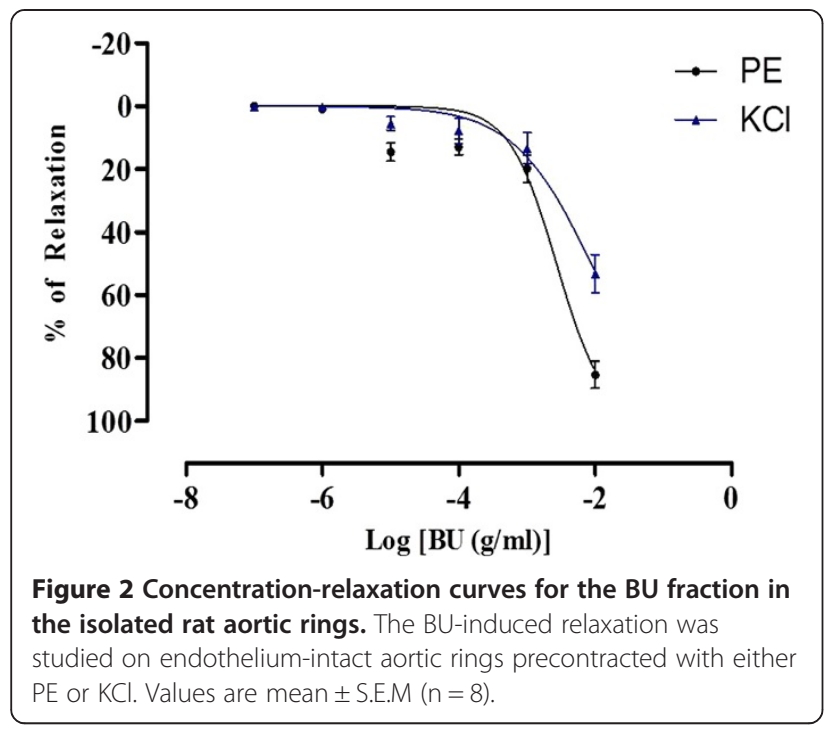

All the sub-fractions (F1 to F8) of BU obtained from the column chromatography at concentrations ranging from $10^{-7}-10^{-2} \mathrm{~g} / \mathrm{ml}$ significantly inhibited the sustained tonic contractions induced by $\mathrm{PE}$. The $\mathrm{R}_{\max }$ value achieved by $\mathrm{F} 1$ was $98.39 \pm 5.79 \%$ with $\mathrm{pIC}_{50}$ value of $2.62 \pm 0.002$ and both of these values were significantly different $(\mathrm{p}<0.05)$ with that shown by all other subfractions (Figure 3, Table 1)

For the aortic ring precontracted with $\mathrm{KCl}, \mathrm{F} 1$ also achieved the highest percentage of relaxation with the $\mathrm{R}_{\max }=84.40 \pm 24.04 \%$ and $\mathrm{pIC}_{50}=2.54 \pm 0.003$, respectively. There was no significant difference in the percentage of relaxation that caused by F1 if compared with F2 and F3. (Figure 3, Table 1).

In view of the finding that the relaxant effect of $\mathrm{F} 1$ is the highest and significantly different from that of the BU and other fractions, it was subjected to further studies.

\section{Effects of $\mathrm{F} 1$ on calcium channel activities}

As shown in Figure $4, \mathrm{CaCl}_{2}$ caused a concentrationdependent contraction of aortic rings that had been exposed to a $\mathrm{Ca}^{2+}$-free medium with high concentration of $\mathrm{K}^{+}$. The $\mathrm{E}_{\max }$ values were significantly reduced by preincubation of the rings with $\mathrm{F} 1$ at $2.0 \times 10^{-3} \mathrm{mg} / \mathrm{ml}$ $(\mathrm{p}<0.05)$ and $4.0 \times 10^{-3} \mathrm{mg} / \mathrm{ml} \quad(\mathrm{p}<0.01)$ in a concentration- dependent manner (Table 2). The $\mathrm{pEC}_{50}$ values were also reduced in the presence of $\mathrm{F} 1$.

In a $\mathrm{Ca}^{2+}$ - and $\mathrm{K}^{+}$-free medium, $\mathrm{Ca}^{2+}\left(1 \times 10^{-4}-1 \mathrm{x}\right.$ $\left.10^{-2} \mathrm{M}\right)$ was cumulatively added to the organ bath after PE had induced a stable tonic contraction. Sustained contraction was generated which increased with the concentration of $\mathrm{Ca}^{2+}$. The $\mathrm{Ca}^{2+}$ - induced contraction was significantly inhibited by the preincubation of the aortic ring with $\mathrm{F} 1$ $\left(2.0 \times 10^{-3}\right.$ and $\left.4.0 \times 10^{-3} \mathrm{mg} / \mathrm{ml}\right)$ in a concentrationdependent manner (Figure 5). F1 significantly $(\mathrm{p}<0.01)$

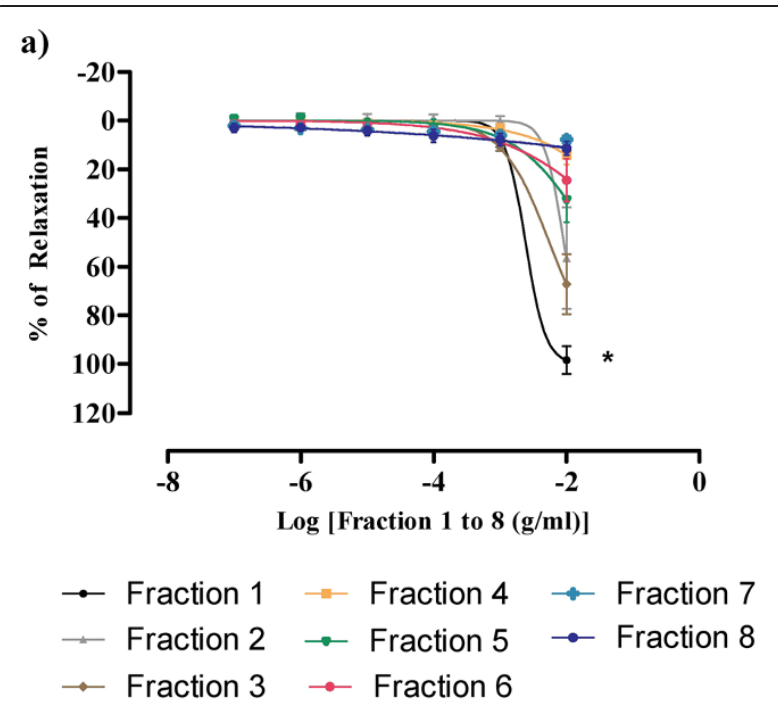

b)

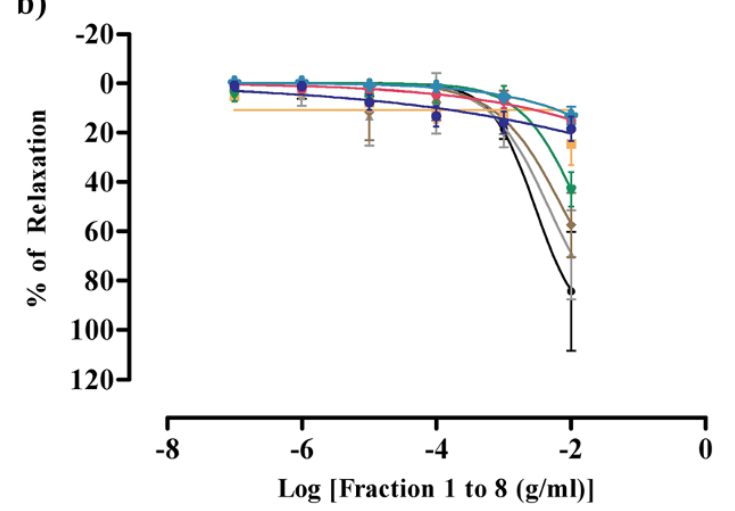

$\rightarrow$ Fraction $1 \rightarrow$ Fraction $4 \rightarrow$ Fraction 7
$\rightarrow$ Fraction $2 \rightarrow$ Fraction $5 \rightarrow$ Fraction 8
$\rightarrow$ Fraction $3 \rightarrow$ Fraction 6

Figure 3 Concentration-relaxation curves for the 8 sub-fractions in the isolated rat aortic rings. The fractions-induced relaxations were studied on endothelium-intact aortic rings precontracted with either (a) PE or (b) $\mathrm{KCl}$. Values are mean \pm S.E.M $(n=6),{ }^{*} P<0.05$ compared with other sub-fractions.

suppressed the $\mathrm{E}_{\max }$ values of $\mathrm{CaCl}_{2}$ with the reduction of the $\mathrm{pEC}_{50}$ values (Table 2). Results in Figure 6 show that the contractions induced by either NA or caffeine in $\mathrm{Ca}^{2+}$-free solution were not significantly affected by F1.

\section{Effects of $\mathrm{F} 1$ on potassium channel activities}

As shown in Figure 7, preincubation with glibenclamide and 4-aminopyridine caused significant reductions in the $R_{\max }$ values caused by F1. Similarly, the $\mathrm{pIC}_{50}$ values were reduced in the presence of these 2 drugs (Table 3). However, there was no significant difference found between the F1-induced relaxation curves of the aortic rings preincubated with TEA and the control curve. The 
Table 1 The effects of BU-derived sub-fractions in aortic rings precontracted with $\mathrm{PE}$ or $\mathrm{KCl}$

\begin{tabular}{cccccc}
\hline Fraction & \multicolumn{2}{c}{$\mathrm{PE}$} & & \multicolumn{2}{c}{$\mathrm{KCl}$} \\
\cline { 2 - 3 } \cline { 5 - 6 } & $\mathbf{R}_{\max }(\%)$ & $\mathbf{p I C}_{\mathbf{5 0}}$ & & $\mathbf{R}_{\max }(\%)$ & $\mathbf{p l C}_{\mathbf{5 0}}$ \\
\hline 1 & $98.39 \pm 5.79^{*}$ & $2.62 \pm 0.09^{*}$ & & $84.40 \pm 24.04$ & $2.54 \pm 0.15$ \\
2 & $56.57 \pm 20.90$ & $2.04 \pm 0.35$ & & $69.54 \pm 18.08$ & $2.34 \pm 0.18$ \\
3 & $67.21 \pm 12.33$ & $2.24 \pm 0.08$ & & $57.45 \pm 13.09$ & $2.13 \pm 0.15$ \\
4 & $14.02 \pm 3.92$ & - & & $24.54 \pm 8.67$ & - \\
5 & $32.47 \pm 9.12$ & - & & $43.01 \pm 6.93$ & - \\
6 & $24.35 \pm 8.74$ & - & & $15.15 \pm 3.72$ & - \\
7 & $7.84 \pm 1.57$ & - & & $12.85 \pm 3.52$ & - \\
8 & $11.38 \pm 2.75$ & - & & $18.38 \pm 4.99$ & - \\
\hline
\end{tabular}

Values are means \pm S.E.M $(n=6) .{ }^{*} P<0.05$ compared with other sub-fractions.

$\mathrm{R}_{\max }$ and $\mathrm{pIC}_{50}$ values were also not significantly altered by the incubation with TEA.

Effects of $\mathrm{F} 1$ on the endothelium-denuded aortic rings precontracted with $\mathrm{PE}, \mathrm{NO}$ and prostacyclin productions, and guanylyl cyclase activity

The $\mathrm{R}_{\max }$ and $\mathrm{pIC}_{50}$ of endothelium-denuded aortic rings are $93.28 \pm 3.02 \%$ and $2.44 \pm 0.09$ respectively, which are not significantly different from the control values of $98.39 \pm 5.79 \%$ and $2.62 \pm 0.09$ respectively. Besides that, the vasorelaxing effect $\left(\mathrm{R}_{\max }\right.$ and $\left.\mathrm{pIC}_{50}\right)$ induced by F1 were also not significantly affected by preincubation of L-NAME, ODQ, and methylene blue. Nonetheless, preincubation of indomethacin caused significant reductions in both the $\mathrm{R}_{\max }$ and $\mathrm{pIC}_{50}$ values of F1 (Figure 8, Table 3).

\section{Effects of F1 on the autonomic receptor activities}

As shown in Figure 9, the vasorelaxing effects of F1 against PE-precontracted aortic rings were not significantly inhibited by the preincubation with atropine or propranolol. In both experiments, the $\mathrm{R}_{\max }$ and $\mathrm{pEC}_{50}$ values did not show any significant difference with that of the control (Table 3).

\section{Discussion}

In the present study, BU was found to cause relaxation on the endothelium-intact aortic rings that had been precontracted with $\mathrm{PE}$ or $\mathrm{KCl}$ (Figure 1). This confirms

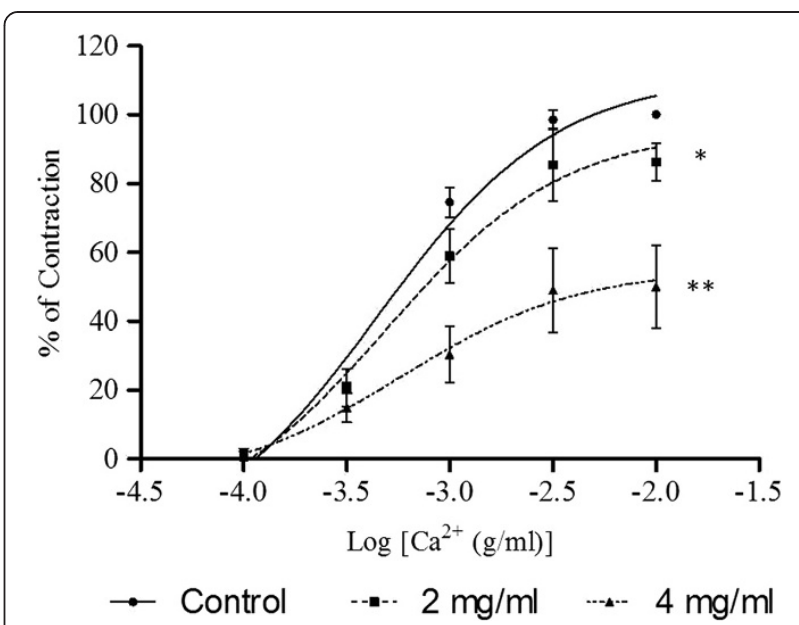

Figure 4 Effect of $\mathrm{F} 1$ on $\mathrm{CaCl}_{2}$-induced contraction in $\mathrm{Ca}^{2+}$-free solution containing high $\mathrm{K}^{+}(60 \mathrm{mM})$. Concentration-response curves for $\mathrm{CaCl}_{2}$ were determined in aortic rings in the absence and presence of F1 (2 or $4 \mathrm{mg} / \mathrm{ml})$. Values are mean \pm S.E.M. $(n=6)$. ${ }^{*} \mathrm{P}<0.05$ and ${ }^{*} \mathrm{P} P 0.01$ compared with control (without F1).

the results reported in a previous study [17] that BU may reduce $\mathrm{BP}$ by vasodilation. BU was then further purified by column chromatography using solvent mixtures of different polarities. It was found that F1 demonstrated the highest vasodilatory activity and the effect was more profound $(\mathrm{p}<0.05)$ when compared with BU-induced vasorelaxation. This indicates that most of the putative active compounds of BU appear to be concentrated in F1. Phenylephrine activates the $\alpha_{1}$-adrenoceptors in the VSM to cause the muscle contraction involving phospholipase $\mathrm{C}$ (PLC) and 1,2-diacylglycerol (DAG) [20,21] while $\mathrm{KCl}$ causes the depolarisation of the VSM cell membrane, opening of VDCC and influx of $\mathrm{Ca}^{2+}$ in order to cause contraction [22]. Both BU- and F1 induced relaxation in aortic rings precontracted with $\mathrm{PE}$ or $\mathrm{KCl}$, suggesting that they might inhibit both the activation of $\alpha_{1}$-adrenoceptors and opening of the VDCC.

It is well known that vasoconstriction is initiated by elevated levels of the free cytoplasmic $\mathrm{Ca}^{2+}$ which can either be due to the influx of extracellular $\mathrm{Ca}^{2+}$ upon opening of the VDCC and ROCC located on the cell membrane $[22,23]$ or the release of $\mathrm{Ca}^{2+}$ from sarcoplasmic reticulum (SR) [24,25]. To investigate whether $\mathrm{F} 1$ could interfere with the $\mathrm{Ca}^{2+}$ influx through VDCC,

Table 2 The effects of $\mathrm{F} 1$ on $\mathrm{E}_{\max }$ and $\mathrm{pEC} \mathrm{C}_{50}$ values for $\mathrm{CaCl}_{2}$

\begin{tabular}{|c|c|c|c|c|}
\hline \multirow{2}{*}{$\begin{array}{c}\mathrm{F} 1 \\
(\mathrm{mg} / \\
\mathrm{ml})\end{array}$} & \multicolumn{2}{|c|}{$\mathrm{Ca}^{2+}$-free solution containing high $\mathrm{K}^{+}$} & \multicolumn{2}{|c|}{$\mathrm{Ca}^{2+}$ and $\mathrm{K}^{+}$-free solution containing $\mathrm{PE}$} \\
\hline & $\mathrm{E}_{\max }(\%)$ & $p E C_{50}$ & $\mathrm{E}_{\max }(\%)$ & $\mathrm{pEC} \mathrm{C}_{50}$ \\
\hline 0 & 100 & $3.35 \pm 0.08$ & 100 & $3.73 \pm 0.21$ \\
\hline 2.0 & $86.33 \pm 5.44^{*}$ & $3.31 \pm 0.19$ & $75.33 \pm 10.33^{* *}$ & $3.61 \pm 0.27$ \\
\hline 4.0 & $50.04 \pm 12.06^{* *}$ & $3.24 \pm 0.42$ & $44.93 \pm 11.46^{* *}$ & $3.34 \pm 0.48$ \\
\hline
\end{tabular}

Values are means \pm S.E.M $(n=6) .{ }^{*} P<0.05$ and ${ }^{* *} P<0.01$ compared with control $(0 \mathrm{mg} / \mathrm{ml}$ of $\mathrm{F} 1$. 


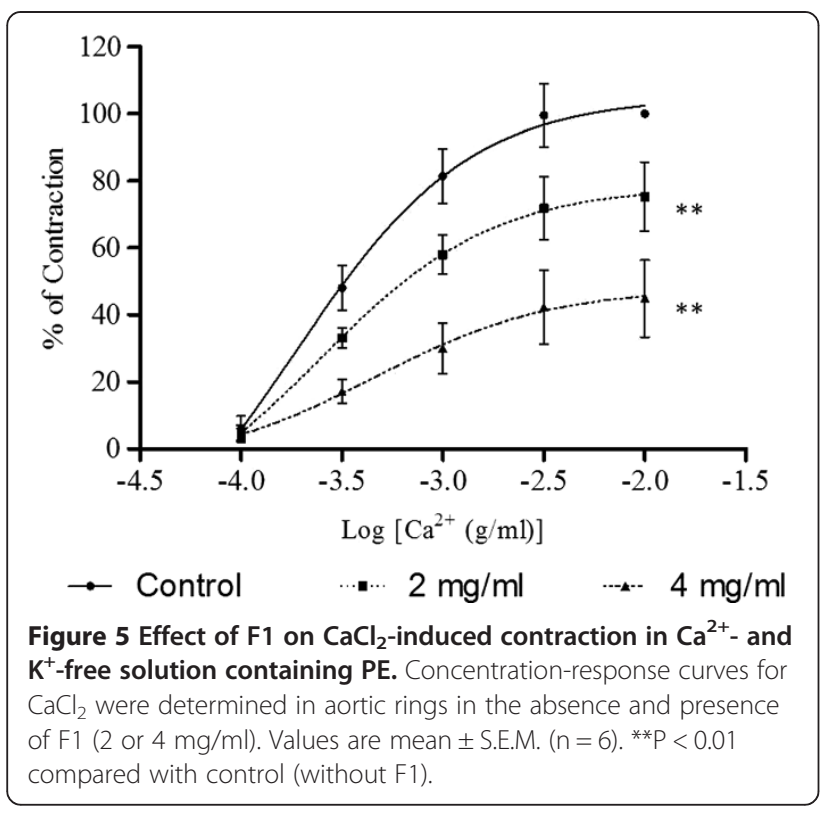

$\mathrm{CaCl}_{2}$-induced contraction in $\mathrm{Ca}^{2+}$-free with high $\mathrm{K}^{+}$ medium was used. Under high concentrations of $\mathrm{K}^{+}$, the added $\mathrm{Ca}^{2+}$ will cause the influx of $\mathrm{Ca}^{2+}$ through the VDCC [22]. Whereas to investigate whether F1 could interfere with the $\mathrm{Ca}^{2+}$ through $\mathrm{ROCC}, \mathrm{Ca}^{2+}$ - and $\mathrm{K}^{+}$-free medium containing $\mathrm{PE}$ was used. Addition of $\mathrm{PE}$ in the $\mathrm{Ca}^{2+}$-and $\mathrm{K}^{+}$-free medium will cause the release of $\mathrm{Ca}^{2+}$ from intracellular store and the entry of $\mathrm{Ca}^{2+}$ into the cells through ROCC since VDCC are inactivated in the absence of $\mathrm{K}^{+}[26,27]$. Results in Figures 3 and 4 show that preincubation with F1 significantly decreased the $\mathrm{E}_{\max }$ of the $\mathrm{CaCl}_{2}$-induced contractions in both media, suggesting that the vasodilatory

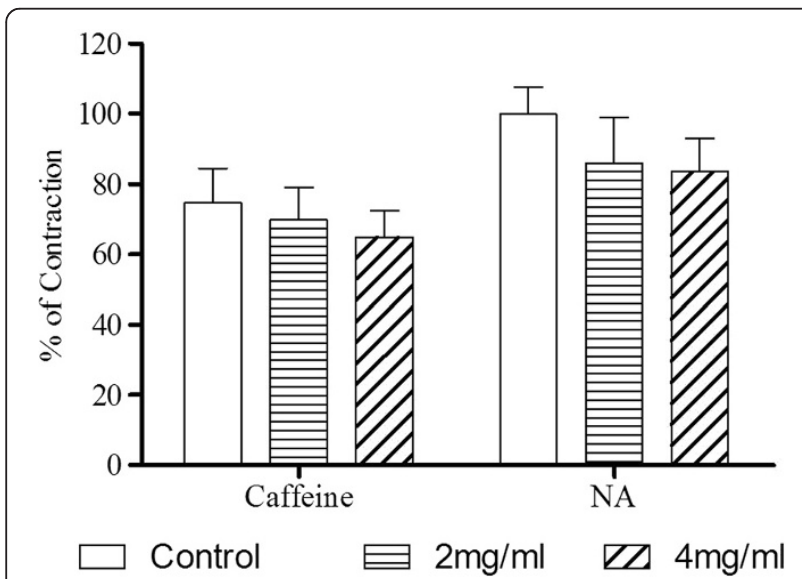

Figure 6 Effect of F1 on NA- and caffeine-induced contraction in $\mathrm{Ca}^{2+}$-free solution. Aortic rings were preincubated with vehicle (control) or BU (2 or $4 \mathrm{mg} / \mathrm{ml})$ and NA $\left(10^{-6} \mathrm{M}\right)$ or caffeine $(45 \mathrm{mM})$ was added to trigger the contractions. Values are mean \pm S.E.M. $(n=6)$.

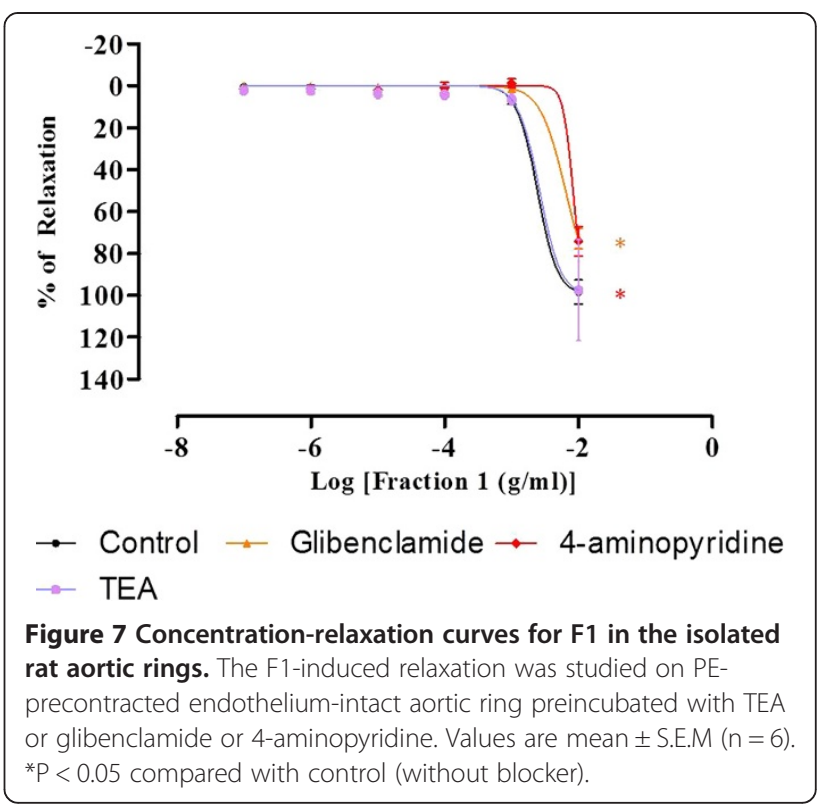

effect of F1 is caused by blocking the influx of $\mathrm{Ca}^{2+}$ via VDCC and ROCC.

Caffeine and NA were used to study the release of $\mathrm{Ca}^{2+}$ from intracellular sarcoreticular stores. Caffeine can stimulate the ryanodine receptors [28] and NA can trigger the activation of $\mathrm{IP}_{3}$ [29] receptor located at the SR in order to cause the release of the $\mathrm{Ca}^{2+}$ from SR. In the present study, it is found that the vasoconstriction induced by both caffeine and NA were not affected by F1 (Figure 5). Therefore, the vasodilatory effect of F1 does not seem to be related to inhibition of ryanodine or $\mathrm{IP}_{3}$ receptors.

Potassium channels play a very crucial role in controlling the vascular contractility. Efflux of $\mathrm{K}^{+}$due to the opening of the $\mathrm{K}^{+}$channels in VSM will bring about membrane hyperpolarisation, which in turn, will lead to the closure of the VDCC and reduction of the $\mathrm{Ca}^{2+}$ entry, and finally cause vasodilation [30]. In contrast, closure of the $\mathrm{K}^{+}$

Table 3 The $R_{\max }$ and plC $C_{50}$ values of F1 in aortic rings pretreated with various drugs

\begin{tabular}{ccc}
\hline Drugs & $\mathbf{R}_{\max }(\mathbf{\%})$ & $\mathbf{p l C}_{\mathbf{5 0}}$ \\
\hline Control & $98.39 \pm 5.79$ & $2.62 \pm 0.09$ \\
TEA & $97.61 \pm 24.04$ & $2.58 \pm 0.30$ \\
Glibenclamide & $73.23 \pm 4.84^{*}$ & $2.19 \pm 0.06^{*}$ \\
4-aminopyridine & $74.31 \pm 6.89^{*}$ & $2.08 \pm 0.05^{*}$ \\
L-NAME & $82.77 \pm 13.12$ & $2.49 \pm 0.12$ \\
Indomethacin & $68.15 \pm 5.96^{*}$ & $2.37 \pm 0.05^{*}$ \\
ODQ & $88.46 \pm 6.49$ & $2.51 \pm 0.14$ \\
Methylene blue & $107.98 \pm 9.29$ & $2.85 \pm 0.17$ \\
Atropine & $92.12 \pm 2.64$ & $2.53 \pm 0.07$ \\
Propanolol & $93.02 \pm 8.93$ & $2.46 \pm 0.09$ \\
\hline
\end{tabular}

Values are means \pm S.E.M $(n=6),{ }^{*} P<0.05$ compared with control (without any drugs). 


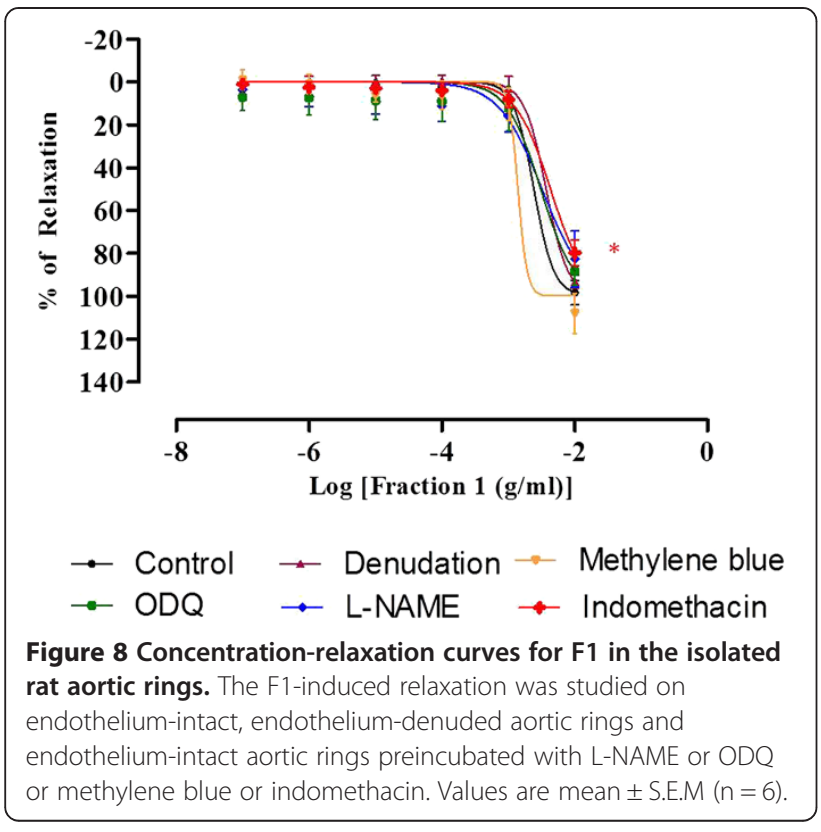

channels will cause membrane depolarisation and vasoconstriction [31]. Four distinct types of $\mathrm{K}^{+}$channels have been identified in VSM, namely voltage-activated $\mathrm{K}^{+}$channel, $\mathrm{Ca}^{2+}$-activated $\mathrm{K}^{+}$channels, ATP-sensitive $\mathrm{K}^{+}$channels, and inward rectifier $\mathrm{K}+$ channels) [32]. As demonstrated by the results in Figure 6, F1 may be able to enhance or stimulate the opening of both voltage-activated and ATP-sensitive $\mathrm{K}^{+}$channels, since preincubation with glibenclamide and 4-aminopyridine significantly attenuated its vasodilatory effect. On the other hand, $\mathrm{Ca}^{2+}$-activated $\mathrm{K}^{+}$channel may not be involved in the vasodilatory effect of $F 1$ since $R_{\max }$ value of $F 1$ was not significantly altered with the preincubation of TEA.

Nitric oxide is the primary EDRF formed in the endothelium that diffuses to the VSM to activate the soluble

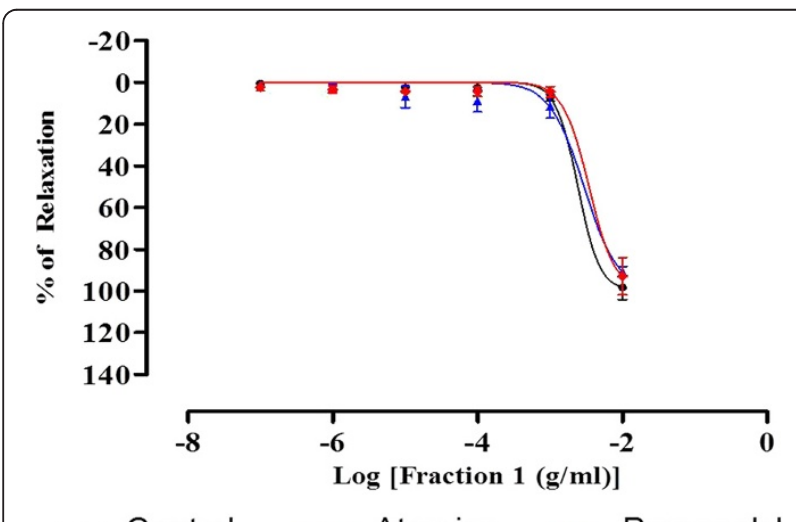

$\rightarrow$ Control $\rightarrow$ Atropine $\rightarrow$ Propanolo rat aortic rings. The F1-induced relaxation was studied on

PE-precontracted endothelium-intact aortic rings preincubated with atropine or propanolol. Value are mean \pm S.E.M $(n=6)$. guanylyl cyclase. This enzyme will then catalyse the formation of cyclic guanosine monophosphate (cGMP), which in turn activates the protein kinase G (PKG). The PKG will cause the phophorylation of myosin light-chain kinase (MLCK) and subsequently decrease its activity, leading to the dephosphorylation of myosin light chain and thus causing vasorelaxation [33]. In addition, NO also participates in the regulation of the level of smooth muscle free $\mathrm{Ca}^{2+}$, which is the primary determinant of contractions [34]. Prostacyclin is the lipid compound derived enzymatically from fatty acid and it is the first EDRF that was discovered earlier than NO [35]. It is synthesised in both VSM and endothelial cells [36]. Results from the present studies show that removal of endothelium did not cause significant changes in the $\mathrm{R}_{\max }$ and $\mathrm{pIC}_{50}$ of $\mathrm{F} 1$-induced relaxation. This indicates that endothelium may not be involved in the vasodilatory effect of F1. Similarly, there were also no significant changes in the $\mathrm{R}_{\max }$ and $\mathrm{pIC}_{50}$ values for the aortic rings preincubated with L-NAME, ODQ, and methylene blue (Figure 7). These findings imply that F1 does not affect the endothelium-derived NO production as well as the NO-mediated pathway. To the contrary, significant reductions in both $\mathrm{R}_{\max }$ and $\mathrm{pIC}_{50}$ were observed in the aortic ring preincubated with indomethacin, the inhibitor of the cyclo-oxygenase that participates in the prostacyclin synthesis. Prostacyclin is synthesised in both endothelium and VSM. The vasodilatory effect of F1 was attenuated by the inhibition of cyclo-oxygenase but not by the removal of endothelium, suggesting that F1 may stimulate the release of prostacyclin from VSM.

The beta adrenoceptor acts by coupling with G protein. The activation of beta adrenoceptor stimulates adenylyl cyclase which functions as a catalyst for the conversion of adenosine triphosphate to cyclic adenosine monophosphate. This in turn leads to the activation of protein kinase A and vasodilation [37]. Muscarinic receptors are stimulated by the postganglionic cholinergic neurons of either the parasympathetic or the sympathetic cholinergic systems that mediate smooth muscle relaxation, glandular secretion, and modulation of cardiac rate and force [38]. Results from the present study show that there were no significant changes in the $\mathrm{R}_{\max }$ and $\mathrm{pEC}_{50}$ in the aortic rings preincubated with propanolol and atropine (Figure 8). This suggests that beta adrenoceptor and muscarinic receptor may not be involved in the vasodilatory effect of F1.

Phytochemcial screening of the compounds present in F1 detected high amount of flavonoids. Flavonoids are polyphenolic compounds that occur naturally in vegetables, fruits, seeds, nuts, barks and are an integral part of the human diet [39]. Flavonoids belong to the low molecular weight group of polyphenol substances. The biochemical activities of flavonoids and their metabolites 
depend on their chemical structure and relative orientation of various moieties on the molecule. They can be grouped into 8 major classes by their chemical structures that include flavones, flavanones, flavonols, catechins, anthocyanidins, isoflavones, dihydroflavonols, and chalcones [40]. Depending on their chemical structures, these flavonoids have been found to possess a wide range of pharmacological activities, such as antihypertensive $[41,42]$ and vasodilatory $[43,44]$ activities.

In the present study, although the phytochemical screening technique did not reveal the actual chemical structures of the active compounds in F1, it helped to show that the majority of compounds present in F1 are flavonoids. Based on the evidence that F1 exhibits vasodilatory activity and as well as containing flavonoids, it is logical to postulate that the vasodilatory effect of F1 could possibly be attributed to the presence of flavonoid. However more experiments need to be carried out in order to confirm this association and to identify the structure of the active compounds.

\section{Conclusions}

This study demonstrates conclusively that leaves of G. procumbens contain potent vasodilatory substances, more of them being found in the F1 subfraction of the BU fraction. These results also further confirm previous findings that the vasodilatory effects of BU were brought about by blocking the calcium channels. In addition to the $\mathrm{Ca}^{2+}$ channel-blocking activities, the active compounds were also found to be able to open $\mathrm{K}^{+}$channel as well as to stimulate the production of prostacyclin. Phytochemical analyses reveal that the putative compounds are probably flavonoids in nature.

\section{Competing interests}

The authors declare that they have no competing interests.

\section{Authors' contributions \\ NHK participated in the design of study and carried out all the extraction, purification, isolated aortic rings experiments and drafted the manuscript. PTF carried out the extraction process. LSK and HSZ participated in the design of study and edited the manuscript. All authors have read and approved the final manuscript.}

\section{Acknowledgements}

This work is funded by PPP grant and RU grant from the University of Malaya (PV010/2011B and RG028/09 BIO respectively). NHK and PTF were supported by University of Malaya Fellowship Scheme.

Received: 6 February 2013 Accepted: 19 July 2013

Published: 23 July 2013

\section{References}

1. Aram VC, George LB, Henry RB, William CC, Lee AG, Joseph LI, Daniel WJ, Barry JM, Suzanne O, Jackson TW, Edward JR: Seventh Report of the Joint National Committee on Prevention, Detection, Evaluation, and Treatment of High Blood Pressure. Journal of American Heart Association 2003, 42:1206-1252

2. Norman K, Shanthi M, Neil P, Judith W: International Society of Hypertension (ISH) statement on management of hypertension J Hypertens 2003, 21:1983-1992.
3. Fusita T, Ando K, Noda H, Sato Y, Yamashita N, Yamashita K: Hemodynamic and endocrine changes associated with captopril in diuretic resistant patients. Am J Med 1982, 73:341-347.

4. Freis ED: Hydralazine in hypertension. Am Heart J 1964, 67:133-134.

5. Perry LM: Medicinal plant of East and Southeast Asia: Attributed properties and uses. Cambridge Massachusetts and London: The MIT Press; 1980.

6. Chan LK, Lim SY, Pan LP: Micropropagation of Gynura procumbens (Lour.) Merr. an important medicinal plant. Journal of Medicinal Plants Research 2009, 3:105-111.

7. Zhang XF, Tan BKH: Effects of an ethanolic extract of Gynura procumbens on serum glucose, cholesterol and triglyceride levels in normal and Steptozotocin-induced diabetic rats. Singapore Med J 2000, 41:9-13.

8. Akowuah GA, Sadikum A, Mariam A: Flavonoid identification and hypoglycaemic studies of the butanol fraction from Gynura procumbens. Pharm Biol 2002, 40:405-410.

9. Bohari M, Pauliena SH, Muhajir, Shaari, Lajis K, Nordin: Glucose uptake: Stimulatory activity of Gynura procumbens in 3T3- F442A adipocytes. Sarawak: Malaysian Medicinal Plant: Chemistry and Biological Activity: UNIMAS and Malaysian Natural Products Society; 2000.

10. Iskander MN, Song Y, Coupar IM, Jiratchariyakul W: Antiinflammatory screening of the medicinal plant Gynura procumbens. Plant Foods Hum Nutri 2002, 57:233-244

11. Mahmood AA, Mariod AA, Fouad A, Ibrahim SAW: Anti-ulcerogenic activity of Gynura procumbens leaf extract against experimentally-induced gastric lesions in rats. Journal of Medicinal Plants Research 2010, 4:686-691.

12. Kim J, Lee CW, Kim EK, Lee SJ, Park NJ, Kim HS, Kim HK, Cha K, Jang YP, Kim JW: Inhibition effect of Gynura procumbens extract on UV-B-induced matrix-metalloproteinase expression in human dermal fibroblasts. J Ethnopharmacol 2011, 137:427-433.

13. Rosidah, Yam MF, Amirin S, Ahmad M, Akowuah GA, Zaini MA: Toxicology evaluation of standardized methanol extract of Gynura procumbens. J Ethnopharmacol 2009, 123:244-249.

14. Lee HJ, Lee BC, Chung JH, Sumali W, Chun W, Kim SS, Kim H, Choe M: Inhibitory effects of an aqueous extract of Gynura procumbens on human mesangial cell proliferation. Korean J Physiol Pharmacol 2007, 11:145-148.

15. Lam SK, Idris A, Bakar ZAA, Ismail R: Gynura procumbens and blood pressure in the rats: preliminary study. Asia Pacific Journal of Pharmacology 1998, 13:14-15.

16. Hoe SZ, Kamaruddin MY, Lam SK: Inhibition of angiotensin-converting enzyme activity by a partially purified fraction of Gynura procumbens in spontaneously hypertensive rats. Med Princ Pract 2007, 16:203-208.

17. Hoe SZ, Lee CN, Mok SL, Kamaruddin MY, Lam SK: Gynura procumbens Merr. decreases blood pressure in rats by vasodilatation via inhibition of calcium channels. Clinics 2011, 66:143-150.

18. Menezes IAC, Moreira IJA, Carvalho AA, Antoniollo AR, Santos MRV: Cardiovascular effects of the aqueous extract from Caesalpinia ferrea: Involvement of ATP-sensitive potassium channels. Vascul Pharmacol 2007, 47:41-47.

19. Leeya Y, Mulvany MJ, Queiroz EF, Marston A, Hostettmann KC, Jansakul C: Hypotensive activity of an n-butanol extract and their purified compounds from leaves of Phyllanthus acidus (L.) Skeels in rats. Eur J Pharmacol 2010, 649:301-313.

20. Rudner XL, Berkowitz DE, Booth JV, Funk BL, Cozart KL, D'Amico EB, El-Moalem H, Page SO, Richardson CD, Winters B, Marucci L, Schwinn DA: Subtype specific regulation of human vascular alpha(1)-adrenergic receptors by vessel bed and age. Circulation 1999, 100:2336-2343.

21. Cauvin C, Malik S: Induction of $\mathrm{Ca}^{2+}$ influx and intracellular $\mathrm{Ca}^{2+}$ released in isolated rat aorta and mesenteric resistance vessels by norepinephrine activation of alpha-1-receptors. J Pharmacol Exp Ther 1984, 230:413-418

22. Karaki H, Ozaki H, Hori M, Mitsui-Saito M, Amano K, Harada K, Miyamoto S, Nakazawa H, Won KJ, Sato K: Calcium movements, distribution and function in smooth muscle. Pharmacol Rev 1997, 49:157-230

23. Karaki H, Weiss GB: Calcium channels in smooth muscle. Gastroenterology 1984, 87:960-970.

24. Meisheri KD, Hwang O, van Breemen C: Evidence for two separated $\mathrm{Ca}^{2+}$ pathways in smooth muscle plasmalemma. J Membr Biol 1981, 59:19-25.

25. Yamamoto $\mathrm{H}$, van Breemen $\mathrm{C}: \mathrm{Ca}^{2+}$ compartments in saponin-skined cultured vascular smooth muscle cells. J Gen Physiol 1986, 87:369-389. 
26. Jiang H, Xia Q, Wang X, Song J, Bruce IC: Luteolin induces vasorelaxation in rat thoracic aorta via calcum and potassium channels. Pharmazie 2005, 60:444-447.

27. Noguera MA, Ivora MD, Chulia S, D'Ocon P: Capacitative $\mathrm{Ca}^{2+}$ entry associated wuth the $a_{1}$-adrenoceptors in rat aorta. Nauyn Shmiedeberg's Arch. Pharmacol 1997, 356:83-89.

28. Watanabe C, Yamamoto H, Hirano K, Kobayashi S, Kanaide H: Mechanisms of caffeine induced contraction and relaxation of rat aortic smooth muscle. J Physiol 1992, 456:193-213.

29. Berridge MJ: Inositol triphoshate and calcium signalling. Nature 1993 361:315-325.

30. Quast U: Do $\mathrm{K}^{+}$channel openers relax smooth muscle by opening $\mathrm{K}^{+}$ channels? Trends Pharmacol Sc 1993, 14:332-337.

31. Eun AK, Jin $\mathrm{H}$, In DJ, Won SP: Physiological roles of $\mathrm{K}^{+}$channels in vascular smooth muscle cell. J Smooth Muscle Res 2008, 44:65-81.

32. Nelson MT, Quayle JM: Physiological roles and properties of potassium channels in arterial smooth muscle. Am J Physiol Cell Physiol 1995, 268:799-822.

33. William FG: Review of Medical Physiology. 21st edition. United States of America: McGraw-Hill Companies, Inc; 2003.

34. Furukawa K, Ohshima N, Tawada-Iwata Y, Shigekawa M: Cyclic GMP stimulates $\mathrm{Na}^{+} / \mathrm{Ca}^{2+}$ exchange in vascular smooth muscle cells in primary culture. J Biol Chem 1991, 266:12337-12341.

35. Moncada S, Gryglewski RJ, Bunting S, Vane JR: An enzyme isolated from arteries transforms prostaglandin endoperoxides to an unstable substance that inhibits platelet aggregation. Nature 1976, 263:663-665.

36. Smith WL: Prostaglandin Biosynthesis and its Compartmentation in Vascular Smooth Muscle and Endothelial Cells. Annu Rev Physio/ 1986, 48:251-262.

37. Stephen BL: Molecular and genetic basis of $\beta 2$-adrenergic receptor function. J Allergy Clin Immunol 1999, 104:42-46.

38. Caufield MP, Birdsall NJMB: International Union of Pharmacology. XVII. Classification of Muscarinic Acetylcholine Receptors. Pharmacol Rev 1998, 50:279-288

39. Ratty AK, Das NP: Effects of flavonoids on nonenzymic lipid peroxidation: Structure activity relationship. Biochem Med Metabol BioL 1988, 39:69-79.

40. Kuhnau J: The Flavonoids. A class of semi-essential food components: Their role in human nutrition. WId. Rev. Nutr. Diet 1976, 24:117-191.

41. Balasuriya N, Rupasinghe HPV: Antihypertensive properties of flavonoidrich apple peel extract. Food Chem 2012, 135:2320-2325.

42. Lokesh D, Amitsankar D: Evaluation of mechanism for antihypertensive action of Clerodendrum colebrookianum Walp., used by folklore healers in north-east India. J Ethnopharmacol 2012, 143:207-212.

43. Herrera MD, Zarzuelo A, Jiménez J, Marhuenda E, Duarte J: Effects of flavonoids on rat aortic smooth muscle contractility: Structure-activity relationships. General Pharmacology: The Vascular System 1996, 27:273-277.

44. Cook NC, Samman S: Flavonoids-Chemistry, metabolism, cardioprotective effects, and dietary sources. J Nutr Biochem 1996, 7:66-76.

doi:10.1186/1472-6882-13-188

Cite this article as: $\mathrm{Ng}$ et al.: Potassium channel openers and prostacyclin play a crucial role in mediating the vasorelaxant activity of Gynura procumbens. BMC Complementary and Alternative Medicine 2013 13:188

\section{Submit your next manuscript to BioMed Central and take full advantage of:}

- Convenient online submission

- Thorough peer review

- No space constraints or color figure charges

- Immediate publication on acceptance

- Inclusion in PubMed, CAS, Scopus and Google Scholar

- Research which is freely available for redistribution 